lumbar spine specimens from mClA mice. (G) A schematic diagram illustrating the theory in the current study.

Disclosure of Interest: None declared

DOI: 10.1136/annrheumdis-2018-eular.2570

\section{FRI0150 MTOR BLOCKADE BY RAPAMYCIN DECREASES ARTHRITIS AND SPONDYLITIS DEVELOPMENT AND SEVERITY IN HLA-B27 TRANSGENIC RATS}

S. Chen ${ }^{1}$, M. van Tok ${ }^{1}$, D. Pots ${ }^{1}$, J. Taurog ${ }^{2}$, M. van de Sande ${ }^{1}$, D. Baeten ${ }^{1}$, L. van Duivenvoorde ${ }^{1} .{ }^{1}$ Clinical Immunology and Rheumatology, Amsterdam Medical Center, Amsterdam, Netherlands; ${ }^{2}$ Internal Medicine, Rheumatic Diseases Division, UT Southwestern Medical Center, Dallas, USA

Background: HLA-B27 misfolding is thought to play an important role in the pathogenesis of spondyloarthritis $(\mathrm{SpA})$, possibly through triggering of ER stress and the unfolded protein response. One of the mechanisms that regulates the unfolded protein response is autophagy. Autophagy is a process that degrades proteins, cytoplasmic particles and organelles in lysosomes and is regulated by protein kinases, mechanistic target of rapamycin (mTOR) and AMP activated protein kinase.

Objectives: To study whether blockade of mTOR will affect spondyloarthritis development and/or severity in the Mycobacterium tuberculosis (M. tub) induced disease HLA-B27 tg rat model.

Methods: 6 weeks old, female or orchiectomized male HLA-B27/Huß2m trans genic rats were immunised with $60-90 \mu \mathrm{g}$ heat-inactivated $M$. tub in IFA. Rats were prophylactically or therapeutically treated three times a week intra-peritoneally with $1.5 \mathrm{mg} / \mathrm{kg}$ rapamycin or vehicle. Clinical measurements included weight, clinical scores for spondylitis and arthritis, and hind paw swelling meas ured by plethysmometry. After 5 weeks of treatment rats were sacrificed; axial and peripheral joints were isolated for histology and metacarpophalangeal joints, spleen and lymph nodes were isolated for RNA isolation.

Results: In the prophylactic experiment $72.7 \%(8 / 11)$ and $18.2 \%(2 / 11)$ rapamycin treated rats developed arthritis and spondylitis compared to respectively $100 \%$ $(13 / 13 ; p=0.0225)$ and $92.3 \%(12 / 13 ; p<0.0001)$ control animals. Also severity of arthritis and spondylitis was significantly decreased in rapamycin treated animals compared to control treated animals; mean arthritis severity of diseased rats was respectively 0.45 versus 7.15 on a scale from $0-12(p<0.0001)$ and mean spondy litis severity was respectively 0.18 versus 2.07 on a scale from $0-3(p<0.0001)$ Clinical findings were confirmed by histology with a significant decrease of inflammation $(p<0.0001)$, bone- and cartilage destruction $(p=0.0021)$ and new bone formation $(p=0.0010$ ) in peripheral joints of rapamycin treated rats compared to vehicle treated rats and a similar trend was observed in spinal joints. Also in a therapeutic setting rapamycin treatment decreased arthritis severity (mean score of 6 compared to 8.8 in controls; $p=0.0317$ ) and spondylitis severity (mean score of 1.23 compared to 2.8 in controls; $p=0.0159$ ). Histology for the therapeutic experiment is currently being performed as well as RNA analyses for autophagy genes and pro-inflammatory cytokines, like IL-17A and TNF.

Conclusions: mTOR blockade significantly suppressed arthritis and spondylitis in the M. tub induced disease HLA-B27 transgenic rat model of SpA.

Disclosure of Interest: S. Chen: None declared, M. van Tok: None declared, D. Pots: None declared, J. Taurog: None declared, M. van de Sande: None declared D. Baeten Employee of: UCB Pharma, L. van Duivenvoorde: None declared DOI: 10.1136/annrheumdis-2018-eular.3475

\begin{tabular}{|l|l}
\hline FRI0151 & PROTEIN INHIBITOR OF ACTIVATED STAT3 PREVENTS \\
& PERIPHERAL ARTHRITIS AND GUT INFLAMMATION BY \\
& REGULATING TH17/TREG CELL IMBALANCE VIA STAT3 \\
& SIGNALLING IN MICE MODEL OF SPONDYLOARTHRITIS
\end{tabular}

E. Kwon ${ }^{1}$, H.K. Min ${ }^{1}$, M.Y. Kim ${ }^{1}$, J. Choi ${ }^{2}$, S.-Y. Lee ${ }^{2}$, H.-B. Seo ${ }^{2}$, K. Jung ${ }^{3}$, H. S. $\mathrm{Na}^{2}$, J.-G. Ryu ${ }^{2}$, S.-K. Kwok ${ }^{1}$, M.-L. Cho ${ }^{2}$, S.-H. Park ${ }^{1} .{ }^{1}$ College of Medicine, The Catholic University of Korea; ${ }^{2}$ Catholic Research Institute of Medical Science, The Catholic University of Korea; ${ }^{3}$ Impact Biotech, Seoul, Korea, Republic Of

Background: Spondyloarthritis (SpA) is inflammatory arthritis, and interleukin (IL) -17 is crucial on pathogenesis of SpA. Type 17 helper T cell (Th17) is one of major IL-17 secreting cells. Signal transducer and activator of transcription (STAT) - 3 signalling induces Th17 cell differentiation. Present study investigated the effect of protein inhibitor of activated STAT3 (PIAS3) on SpA pathogenesis. Methods: Curdlan was injected to SKG ZAP-70 ${ }^{\mathrm{W} 163 \mathrm{C}}$ mice for SpA induction. Then PIAS3 or Mock vector was inserted to mice for 10 weeks. Clinical score and histologic scores of paw, spine, and gut were evaluated. Expressions of IL-17, tumour necrosis factor- $\alpha$ (TNF- $\alpha$ ), STAT3, bone morphogenic protein (BMP) were measured. Confocal stain and flow cytometry were used to assess helper T cell differentiation.

Results: PIAS3 significantly diminished the histological scores of paw and gut PIAS3 group displayed lesser expression of IL-17, TNF- $\alpha$, and STAT3 in the paw, spine, and gut. BMP-2/4 expressions were lower in spine of PIAS3 group. Helper $T$ cell differentiation was polarised toward upregulation of regulatory $T$ cell (Treg) and downregulation of Th17 in the PIAS3 mice.

Conclusions: PIAS3 showed preventive effects in mice with SpA by suppressing peripheral arthritis and gut inflammation. Proinflammatory cytokines and Th17/ Treg differentiation were controlled by PIAS3. Additionally BMPs were decreased in spine of PIAS3 mice. These findings suggest that PIAS3 could be a potentia therapeutic choice of $\mathrm{SpA}$ treatment.

\section{REFERENCES:}

[1] Smith JA, Colbert RA: Review: The interleukin-23/interleukin-17 axis in spondyloarthritis pathogenesis: Th17 and beyond. Arthritis \& rheumatology 2014, 66:231-41.

[2] O'Shea JJ, Lahesmaa R, Vahedi G, Laurence A, Kanno Y. Genomic views of STAT function in CD4+ $\mathrm{T}$ helper cell differentiation. Nature reviews Immunology 2011;11:239-50

[3] Miossec P, Korn T, Kuchroo VK: Interleukin-17 and type 17 helper T cells The New England journal of medicine 2009;361:888-98.

[4] Ruutu M, Thomas G, Steck R, Degli-Esposti MA, Zinkernagel MS Alexander K, Velasco J, Strutton G, Tran A, Benham H, Rehaume L, Wilson RJ, Kikly K, Davies J, Pettit AR, Brown MA, McGuckin MA, Thomas $R$. beta-glucan triggers spondylarthritis and Crohn's disease-like ileitis in SKG mice. Arthritis and rheumatism 2012;64:2211-22.

Acknowledgements: None

Disclosure of Interest: None declared

DOI: 10.1136/annrheumdis-2018-eular.1824

\section{FRI0152 INFLAMMASOMES ACTIVATION OCCURS IN THE INFLAMED TISSUES OF AS PATIENTS AND DRIVES IL- 23 EXPRESSION}

F. Ciccia ${ }^{1}$, A. Rizzo ${ }^{2}$, G. Guggino ${ }^{1}$, R. Alessandro ${ }^{1}$, S. Raimondo ${ }^{1}$, F. Macaluso ${ }^{1}$, S. Peralta ${ }^{1}$, S. Milling ${ }^{3}$, D. Elewaut ${ }^{4} .{ }^{1}$ University of Palermo; ${ }^{2}$ Azienda Ospedaliera Ospedali Riuniti Villa Sofia Cervello, Palermo; ${ }^{3}$ University of Glasgow, Glasgow, Italy; ${ }^{4}$ University of Ghent, Ghent, Belgium

Background: A growing body of evidences indicate that the aberrant activation of innate immune systems, occurring in genetically predisposed patients, drives inflammatory processes in Ankylosing Spondylitis (AS).

Objectives: Aim of this study was to evaluate the activation and the functional relevance of inflammasome pathways in patients with AS.

Methods: Intestinal, synovial and bone marrow expression of inflammasome pathways, pyroptosis and IL-1b and IL-18 was evaluated in AS patients. Organic acid extraction was performed on ileal samples as previously described on. The expression of the metabolite-sensing receptors GPR43 and GPR109A involved in the regulation of the intestinal inflammasome was also assessed. The role of intestinal dysbiosis in modulating inflammasome activation was also studied in AS patients and HLA-B27 transgenic rats. Inflammasome activation was evaluated in isolated peripheral AS monocytes. The role of LPS, PGE2 and nicotine in inducing monocyte inflammasome activation and the role of inflammasome in modulating IL-23 production was also evaluated.

Results: Activation of inflammasomes was observed in the inflamed gut, synovia and bone marrow samples of AS patients and associated with an increased expression of caspase-1, IL-1b and IL-18. In AS, AIM2 expression was observed in the context of tuft cells and of adherent ileal bacteria. Inflammasome activation in AS gut, was associated with the occurrence of dysbiosis and increased pyroptosis as demonstrated by the membrane localization of Gasdermin D. Isolated intestinal bacteria from AS ileal samples, significantly modulated inflammasome activation in isolated monocytes. Reduced Short-chain fatty acids concentrations and increased expression of GPR43 and GPR109 were demonstrated in the AS ileal samples. Inflammasome activation was also observed in the inflamed gut of HLA-B27 TG rats and suppressed by antibiotics treatment. Increased expression of NLRP3, NLRC4 and AIM2 was confirmed in AS isolated peripheral monocytes. Serum levels of IL-1b and IL-18 were increased in AS patients, especially in smoker patients, and directly correlated with the ASDAS-CRP. In in vitro studies, LPS and nicotine strongly activated NLRP3, NLRC4 and AIM2 pathways in AS monocytes. The CC genotype of PTGER4 SNP rs6896969 was associated with a significantly increased activation of inflammasome in AS. Finally, inflammasome activation in AS monocytes was required for the induction of IL-23p19 expression in an IL-1b-dependent way.

Conclusions: Inflammasome activation occurs in AS patients being modulated by a plethora of different stimuli. Inflammasome drives IL-23 production in an IL- 